\title{
Testicular interstitial fluid as a monitor for changes in the intratesticular environment in the rat
}

\author{
R. M. Sharpe and Irene Cooper \\ M.R.C. Reproductive Biology Unit, Centre for Reproductive Biology, 37 Chalmers Street, \\ Edinburgh EH3 $9 E W, U . K$.
}

\begin{abstract}
Summary. The use of testicular interstitial fluid (IF) collected from the rat testis has been validated as (1) an index of the total extracellular extratubular fluid volume of the testis (which reflects the permeability of testicular capillaries) and (2) as a means of measuring changes in the interstitial hormonal environment. The former was tested by comparing the albumin 'space' with the volume of recovered IF in the same testes from control and bilaterally cryptorchid rats sampled at $0-40 \mathrm{~h}$ after injection of hCG. Although the volume of IF recovered was on average only $50 \%$ of the albumin 'space', both measures increased in parallel after hCG injection and were always closely correlated $(P<0.001)$ over a 4 - to 5 -fold range.

The volume of recovered IF increased with age in parallel with increase in testicular weight, and the testosterone concentration in IF paralleled changes in peripheral serum, increasing from 45 to 80 days of age and then declining. After injection of $25 \mu \mathrm{g}$ bovine $\mathrm{LH}$, testosterone levels in IF, spermatic venous (SV) and peripheral venous (PV) blood increased up to 10 -fold by $1 \mathrm{~h}$ and returned to control levels over the next $11 \mathrm{~h}$. Testosterone levels in IF were always considerably higher than those in SV blood, but this difference was not constant. Subcutaneous injection of rats with an LH-RH agonist resulted in parallel increases in the serum levels of LH and in the IF and PV levels of testosterone. However, at $6 \mathrm{~h}$ there was an ' $\mathrm{LH}$-independent' secondary increase in testosterone levels which was associated with an increase in IF volume, reflecting an increase in capillary wall permeability and hence increased transport of $\mathrm{LH}$ into the testis.
\end{abstract}

\section{Introduction}

One of the major difficulties encountered in the study of male reproductive physiology is the measurement of intratesticular hormonal changes. To date, practically all in-vivo studies of testicular function have relied on measurements made in fluids draining from the testis (spermatic vein blood, lymph and rete testis fluid), although the composition of these fluids does not necessarily reflect the qualitative or quantitative composition of fluids within the testis. This is likely to be particularly true for hormones or factors which are produced and act within the testis, e.g. testosterone.

In the rat testis there are large interstitial sinusoids filled with interstitial fluid, which bathes and separates the Leydig cells and seminiferous tubules (Fawcett, Neaves \& Flores, 1973; Clark, 1976). This fluid is therefore likely to provide a reliable indication of intratesticular (extratubular) hormone concentrations. Testicular interstitial fluid can be collected in relatively large quantities $(50-150 \mu \mathrm{l} /$ testis in an adult rat) by using extremely simple techniques (Sharpe, 1980, 1981), and its 
composition, including its testosterone concentration, has been reported previously (Sharpe, 1979). In addition, it has been shown that injection of rats with human chorionic gonadotrophin (hCG) results in a large increase in the volume of interstitial fluid within the testis (Sharpe, 1979, 1980, 1981), because of an increased permeability of testicular capillaries (Setchell \& Sharpe, 1981). This change is a crucial factor in regulating the energy and uptake of hCG (LH) in the testis (Sharpe, 1981, 1983).

The collection of testicular interstitial fluid is therefore of considerable potential value, both as an indicator of changes in capillary wall permeability (i.e. by measurement of interstitial fluid volume) and as a means of assessing changes in the interstitial hormonal environment of the testis. However, before this potential can be realized it has to be shown (1) that the measurement of testicular interstitial fluid volume provides a valid index of the total extracellular (extratubular) fluid volume, and (2) that changes in the hormone content of interstitial fluid can be shown to relate meaningfully to known physiological changes. The latter is particularly important as the collection of interstitial fluid takes place in vitro over a $16-20 \mathrm{~h}$ period at $4^{\circ} \mathrm{C}$, yet the hormonal content of the fluid is taken to reflect that existing in vivo at the time of removal of the testis. The present paper reports on the validation of these techniques.

\section{Materials and Methods}

Animals and treatments. Sprague-Dawley rats from our own colony were used for all experiments and were housed under conventional conditions. In two initial experiments the testicular albumin space (or volume of distribution) was compared with the volume of recovered testicular interstitial fluid in individual animals, the experiments being designed so that a wide range of values for these measures were obtained. In Exp. 1, normal intact rats aged 80 days were injected subcutaneously with 0.5 or 45 i.u. hCG (Chorulon: Intervet, Cambridge, U.K.) together with ${ }^{125}$ I-labelled bovine serum albumin (BSA; approx. $4 \times 10^{6}$ c.p.m.) in a volume of $0.2 \mathrm{ml} 0.9 \%(\mathrm{w} / \mathrm{v}) \mathrm{NaCl}$ containing $0.2 \%$ unlabelled BSA (fraction V: Sigma, St Louis, U.S.A.). Groups of 3 rats were killed at 8, 16, 24 or $40 \mathrm{~h}$ after injection. A further group of 6 rats served as non-hormone-treated controls and were injected subcutaneously with ${ }^{125}$ I-labelled BSA and killed $8 \mathrm{~h}$ later. Identical procedures were used in Exp. 2 but only the higher of the two doses of hCG, together with ${ }^{125}$ I-labelled BSA, was injected into normal intact male rats and into rats made bilaterally cryptorchid 5 weeks earlier at 80 days of age, as described previously (de Kretser, Sharpe \& Swanston, 1979; Sharpe, 1983). Groups of 3 intact and 3 cryptorchid rats were then killed at 8, 16, 24 and $40 \mathrm{~h}$ after injection; control animals were treated as described in Exp. 1. Animals were killed with $\mathrm{CO}_{2}$, blood was collected from the trunk and the paired testes were dissected out and subjected to the procedures described below.

In Exp. 3, interstitial fluid collected from the testis by 2 different methods was compared. Rats aged 69 days were injected subcutaneously with $0.1 \mathrm{ml} 0.9 \%(\mathrm{w} / \mathrm{v}) \mathrm{NaCl}$ containing $0.2 \% \mathrm{BSA}$ or with $1.5 \mu \mathrm{g}$ ovine LH (NIAMDD-oLH-S23) in the same vehicle. Animals were killed $2 \mathrm{~h}$ later and their testes subjected to the procedures described below.

Comparison of testosterone levels in interstitial fluid and serum. Three experiments were performed to assess the relationship between levels of testosterone in serum and interstitial fluid in different situations. In Exp. 4, groups of 5 untreated rats aged 25, 45, 60, 80 or 100 days were killed, blood was collected for hormone analysis and the paired testes were dissected out and weighed individually before interstitial fluid was collected as described below. In Exp. 5, rats aged 75 days were injected subcutaneously with $25 \mu \mathrm{g}$ bovine LH (NIH-LH-B4) in $0.1 \mathrm{ml} 0.9 \%(\mathrm{w} / \mathrm{v}) \mathrm{NaCl}$ containing $0.2 \%$ BSA. Groups of 3 rats were anaesthetized at intervals after this treatment by intraperitoneal injection of pentobarbitone sodium (Sagatal: May \& Baker, Dagenham, U.K.), followed by an intracardiac injection of 100 i.u. heparin (Pularin; Duncan, Flockart \& Co., London). An abdominal incision was then made and the right spermatic cord exposed and dissected sufficiently to permit a small piece of tinfoil to be inserted below the cord onto which 
blood could collect. Spermatic vein blood was then collected by cutting either a dorsally descending branch of the spermatic vein (when this was present) or a superficial vein in the spermatic cord itself. Cuts were made with microdissection scissors and care was taken to ensure that the testis remained undisturbed in the scrotum throughout these procedures. When sufficient $(0.5-0.8 \mathrm{ml})$ spermatic vein blood had been collected, the animals were immediately killed, peripheral blood was collected from the trunk and the testes were dissected out and testicular interstitial fluid collected as described below. Six rats injected subcutaneously with saline $(9 \mathrm{~g} \mathrm{NaCl} / 1)$ served as controls and these were killed in two groups at 2 and $40 \mathrm{~h}$ after injection and subjected to the above procedures.

In Exp. 6, rats aged 55 days were injected subcutaneously with $5 \mathrm{ng}$ LH-RH agonist (D-Ser-t$\mathrm{bu}^{6}$, des-Gly- $\mathrm{NH}_{2}{ }^{10}$ ) LH-RH ethylamide; Hoechst, A.G., West Germany) in $0.5 \mathrm{ml} 0.9 \%(\mathrm{w} / \mathrm{v}$ ) $\mathrm{NaCl}$ containing $5 \mathrm{mg}$ gelatin (Sigma) $/ \mathrm{ml}$ and $2.5 \mathrm{mg} \mathrm{BSA} / \mathrm{ml}$. Groups of 4 such rats were killed at $\frac{1}{2}, 1,2,4,6$ and $16 \mathrm{~h}$ after injection and trunk blood and testicular interstitial fluid were collected for hormone analysis. Four rats injected with the vehicle alone and killed $4 \mathrm{~h}$ after injection served as controls.

Collection of testicular interstitial fluid. Interstitial fluid was collected from individual testes essentially as described previously (Sharpe, 1981, 1983). Immediately after removal of the testis the caudal end of the testicular capsule was incised carefully and the testis was placed upright in an 83 $\times 13 \mathrm{~mm}$ polystyrene tube such that the testis was suspended $1-2 \mathrm{~cm}$ above the tube bottom. Fluid was then allowed to percolate from the testis into the tube bottom over the next $16-20 \mathrm{~h}$ at $4^{\circ} \mathrm{C}$. The testis was then removed and the tubes centrifuged for $5 \mathrm{~min}$ at $1000 \mathrm{~g}$ to precipitate any contaminating erythrocytes and the interstitial fluid volume was measured by aspiration in $20 \mu 1$ amounts. The fluid was then diluted with 10 volumes of $0.01 \mathrm{M}$-phosphate-buffered saline $(\mathrm{pH} \mathrm{7.5)}$ containing $0 \cdot 2 \% \mathrm{BSA}$ and stored at $-20^{\circ} \mathrm{C}$ before assay of testosterone. In animals injected with ${ }^{125}$ I-labelled BSA the same procedures were followed except that before collection of interstitial fluid the radioactivity in each testis was determined by counting for $1 \mathrm{~min}$ in a gamma counter, and the level of radioactivity in the recovered interstitial fluid was measured similarly. In the same animals the radioactivity in $1.5 \mathrm{ml}$ serum was also measured and ranged from 21 to $73 \times 10^{3}$ c.p.m./ml, depending on the time after injection.

In Exp. 3, interstitial fluid prepared as described above was compared with fluid collected over a shorter time period. The right testis from each animal was processed as described above whilst the left testis was decapsulated carefully and placed in a $0.5 \mathrm{ml}$ serum vial for 45 min at room temperature. The small amounts of fluid which had collected around the bottom of the testis were then aspirated and centrifuged for $5 \mathrm{~min}$ at $1000 \mathrm{~g}$; the supernatant was aspirated in $5 \mu \mathrm{l}$ amounts and processed as described for interstitial fluid.

Measurement of the testicular albumin space. The albumin space within the testis provides a measure of the extratubular extracellular fluid volume (Setchell, 1978; Setchell \& Sharpe, 1981) because albumin does not penetrate appreciably into the seminiferous tubules (Setchell, Hinton, Jacks \& Davies, 1976). In the present studies the albumin space was determined by comparing the c.p.m. ${ }^{125}$ I-labelled BSA per testis with the c.p.m. ${ }^{125}$ I-labelled BSA per $\mu 1$ serum in individual animals; division of the former by the latter yields the albumin space in $\mu 1$ per testis (Setchell \& Sharpe, 1981). This measurement is only accurate when the levels of ${ }^{125}$ I-labelled BSA in serum and testicular extracellular fluid (i.e. interstitial fluid) have equilibrated and this takes 4-6 $\mathrm{h}$ after injection but is then maintained for $40 \mathrm{~h}$ or longer (Setchell \& Sharpe, 1981; Sharpe, 1981, 1983). Therefore, in the present studies the albumin space was measured no earlier than $8 \mathrm{~h}$ after injection of ${ }^{125}$ I-labelled BSA, and confirmation that equilibration had occurred was obtained by comparing the concentration of labelled BSA in serum and testicular interstitial fluid in individual animals. The ratio of these values always fell within the range $0 \cdot 93-1 \cdot 05$. For each rat the albumin space and recovered interstitial fluid volume per left and right testis was measured, and the mean of these values was used in all subsequent calculations and comparisons.

Radioiodination. BSA (fraction V, Sigma) was labelled with ${ }^{125}$ I using lactoperoxidase 
(Miyachi, Vaitukaitis, Nieschlag \& Lipsett, 1972) to a specific activity of between 43 and 62 $\mu \mathrm{Ci} / \mu \mathrm{g}$.

Hormone measurements. Serum levels of LH were measured by radioimmunoassay (Fraser \& Sandow, 1977) using NIAMDD reagents, and results are expressed in terms of the LH-RP-1 standard.

Testosterone concentrations in serum and interstitial fluid were measured by radioimmunoassay (Corker \& Davidson, 1978). Serum was extracted with 10 volumes of hexane :diethyl ether $(4: 1, \mathrm{v} / \mathrm{v})$ before assay whilst interstitial fluid was assayed unextracted after appropriate dilution. It has been established previously (Sharpe, 1979) that unextracted and extracted interstitial fluid gave comparable testosterone values in the assay, and this was confirmed in the present study when samples from animals of different ages (Table 1) were assayed (1) direct, (2) after extraction and (3) after boiling for $10 \mathrm{~min}$ followed by extraction. The last method was performed to ensure that all protein-bound testosterone was freed for measurement in the RIA. Values obtained by each of the 3 methods showed strong mutual correlation $(r>0.99, n=25, P<$ $0.001)$ and direct comparison using analysis of variance and paired $t$ test revealed no significant $(P$ $>0 \cdot 1)$ difference between the methods. In addition to the above procedures, serum and interstitial fluid samples from the 25-day-old rats were extracted and assayed before and after alumina column chromatography (Furuyama, Mayes \& Nugent, 1970) to remove interference from non-specific serum factors which occurs at this age. This chromatographic step had no significant $(P>0.05)$ effect on the levels of testosterone measured in interstitial fluid, but more than halved $(P<0.01)$ the levels of testosterone measured in serum.

Statistical analysis. The effects of treatment were analysed using 2-factor analysis of variance (with replication) and Student's $t$ test, whilst the correlation between measurements of interstitial fluid volume (Exps 1 \& 2) were assessed using the correlation coefficient. Comparison of testosterone concentrations in fluid from the left and right testes of individual animals (Exp. 3) was made using 2-factor analysis of variance.

\section{Results}

Comparison of the testicular albumin space and recovered interstitial fluid volume

Experiment 1 . In normal intact male rats, injection of a low dose ( 0.5 i.u.) of hCG caused a small but significant $(P<0.05)$ increase $8 \mathrm{~h}$ later in the albumin space and volume of recovered interstitial fluid, although at later times this difference was not evident (Text-fig. 1). In contrast, injection of a high dose ( 45 i.u.) of hCG caused a large $(P<0.001)$ and sustained $(8-24 \mathrm{~h})$ increase in the albumin space and interstitial fluid volume. Although the patterns of change in the fluid volume and albumin space in the testis were very similar, values obtained for the former were only $41-60 \%$ of values obtained for the albumin space in the same testis (Text-fig. 1 ).

Experiment 2. The patterns of change in albumin space and recovered interstitial fluid volume of the testis in control and bilaterally cryptorchid rats over $40 \mathrm{~h}$ after injection of 45 i.u. hCG (Textfig. 1) were virtually identical, with values increasing significantly $(P<0.01)$ at $8-24 \mathrm{~h}$ in control rats and at $16-24 \mathrm{~h}(P<0.001)$ in bilaterally cryptorchid rats. As in Exp. 1, values obtained for the volume of recovered interstitial fluid from testes of controls rats were only $39-58 \%$ of the corresponding albumin space. In bilaterally cryptorchid rats the recovered fluid volume more closely approximated $(51-83 \%)$ the testicular albumin space and in these animals the albumin space and interstitial fluid volume were significantly $(P<0.001)$ greater than in testes from control rats at all times other than at $8 \mathrm{~h}$ after injection (Text-fig. 1).

Although the recovered interstitial fluid volume was always less than the measured albumin space in testes from all animals in the 4 groups shown in Text-fig. 1, the values for these two measurements were always closely correlated $(P<0.001)$, both within each treatment group and overall in the two experiments (Text-fig. 2). 

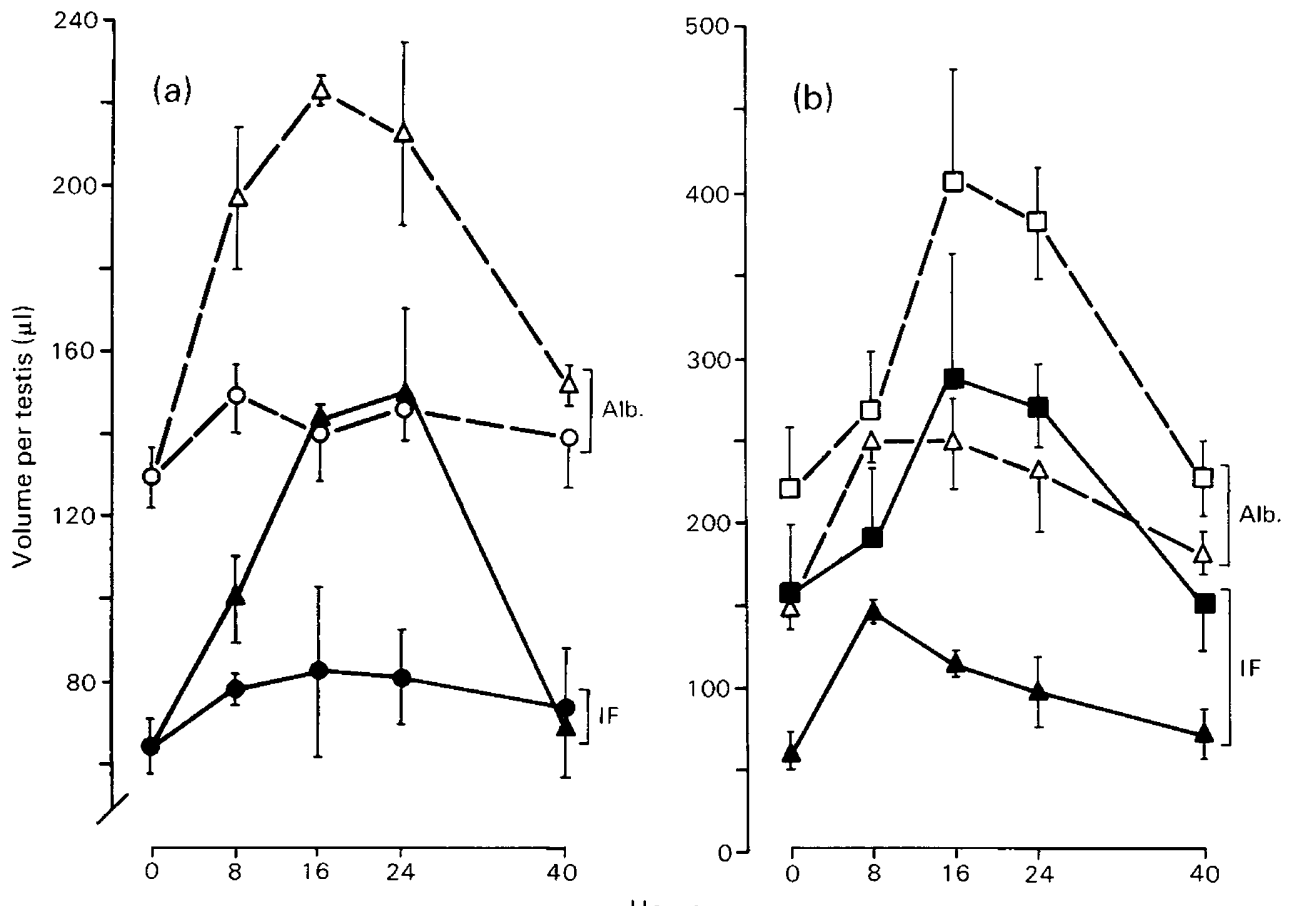

Text-fig. 1. Comparison of the volume of recovered testicular interstitial fluid (IF; solid lines) with the measured testicular albumin space (broken lines) in (a) normal adult rats injected with 0.5 i.u. $(\boldsymbol{O}, \bigcirc)$ or 45 i.u. hCG $(\boldsymbol{\Delta}, \triangle)$, and (b) in normal adult rats $(\boldsymbol{\Lambda}, \triangle)$ or adult rats made bilaterally cryptorchid 6 weeks previously $(\square, \square)$ both of which were injected with 45 i.u. hCG. Each point is the mean \pm s.d. for 3 or 4 animals and full details are given in the text.

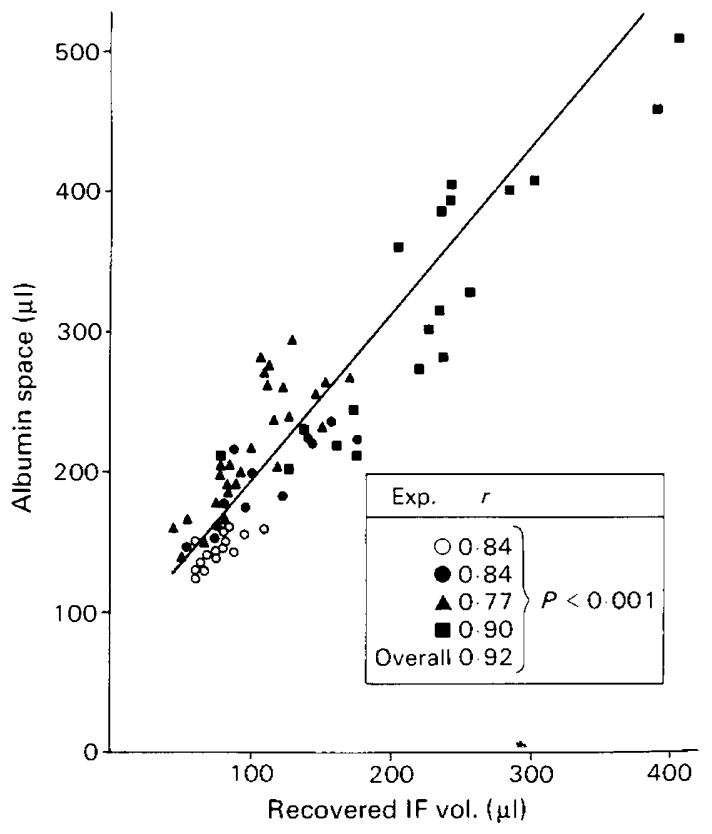

Text-fig. 2. Correlation between the volume of recovered testicular interstitial fluid (IF) and the measured testicular albumin space in individual animals. The data are derived from the experiments illustrated in Text-fig. 1. 
Testosterone concentrations in interstitial fuid collected by two methods

Testosterone levels in testicular fluid collected over $45 \mathrm{~min}$ from the decapsulated left testes of rats injected with saline or $1.5 \mu \mathrm{g} \mathrm{LH}$ were $368 \pm 288$ and $1083 \pm 111 \mathrm{ng} / \mathrm{ml}$, respectively (mean \pm s.d., $n=4$ ). The comparable values obtained for interstitial fluid collected over $16 \mathrm{~h}$ from the right testis using our standard procedure were $517 \pm 176$ and $1433 \pm 234 \mathrm{ng} / \mathrm{ml}$, respectively. Overall, the difference between values obtained by the two methods approached statistical significance $(0.05<P<0 \cdot 2)$. Only very small quantities $(5-10 \mu 1)$ of fluid could be collected from decapsulated testes and, because of the damage to some seminiferous tubules that this procedure inevitably causes, it is likely that interstitial fluid collected by decapsulation will have a higher contamination with seminiferous tubule/rete testis fluid than that collected by our standard procedure; this probably accounts for the difference in mean testosterone values obtained for fluid collected by the two methods.

\section{Age-related changes in the volume of interstitial fluid and its testosterone concentration}

With increase in age (Exp. 4), the recovered volume of interstitial fluid increased in parallel with testicular weight (Table 1). The mean concentration of testosterone in interstitial fluid decreased slightly from 25 to 45 days of age, then increased 3-to 4-fold to reach peak values at 60-80 days of age before falling to lower values at 100 days of age. These changes were more or less paralleled by changes in the serum concentration of testosterone, although the ratio of the testosterone concentration in interstitial fluid to that in serum was at its highest at 25 days of age and then fell significantly $(P<0.05)$ by 45 and 60 days of age before rising again slightly (Table 1$)$.

Table 1. Age-related changes in testicular interstitial fluid (IF) volume and its testosterone concentration in relation to testicular weight and peripheral serum levels of testosterone (mean \pm s.d., $\mathbf{N}=5$ )

\begin{tabular}{|c|c|c|c|c|c|}
\hline & \multicolumn{5}{|c|}{ Days of age } \\
\hline & 25 & 45 & 60 & 80 & 100 \\
\hline $\begin{array}{l}\text { Testicular wt (mg) } \\
\text { IF vol. }(\mu l / \text { testis })\end{array}$ & $\begin{aligned} 326 & \pm 45 \\
8 & \pm 4\end{aligned}$ & $\begin{array}{r}991 \pm 99 \\
43 \pm 13\end{array}$ & $\begin{array}{r}1394 \pm 57 \\
54 \pm 12\end{array}$ & $\begin{array}{r}1568 \pm 57 \\
76 \pm 14\end{array}$ & $\begin{aligned} 1552 & \pm 80 \\
72 & \pm 9\end{aligned}$ \\
\hline \multicolumn{6}{|l|}{ Testosterone conc. (ng/ml) } \\
\hline IF & $245 \pm 91$ & $195 \pm 67$ & $574 \pm 151$ & $772 \pm 274$ & $315 \pm 61$ \\
\hline Serum & $1.6 \pm 0.9$ & $1.8 \pm 0.8$ & $7 \cdot 1 \pm 3 \cdot 2$ & $8 \cdot 2 \pm 7 \cdot 1$ & $2.8 \pm 0.8$ \\
\hline Ratio IF : serum & $193 \pm 70$ & $111 \pm 19$ & $90 \pm 25$ & $138 \pm 64$ & $121 \pm 37$ \\
\hline
\end{tabular}

\section{Testosterone concentrations in interstitial fluid and serum after injection of $L H$}

In rats injected with $25 \mu \mathrm{g} \mathrm{LH}$ (Exp. 5), the levels of testosterone in interstitial fluid, spermatic venous blood and peripheral venous blood changed in a similar manner with time. Testosterone values rose 7 - to 10 -fold in the first hour after injection and then returned gradually to control levels over the next $11 \mathrm{~h}$ (Text-fig. 3). However, despite the obvious similarity in the pattern of response closer inspection revealed significant differences in the relative change in testosterone values in the 3 compartments. The ratio of the testosterone concentration in interstitial fluid to that in spermatic venous blood did not remain constant after LH injection, but decreased significantly $(P<0.05-$ 0.001 ) with respect to control values in the initial $4 \mathrm{~h}$ and then increased at $8-30 \mathrm{~h}$ after injection, this increase being relatively slight $(P<0.05)$ at $8-16 \mathrm{~h}$ but of considerable magnitude $(P<0.001)$ at 20 and $30 \mathrm{~h}$. At 20 and $30 \mathrm{~h}$, testosterone levels in spermatic venous blood fell significantly ( $P<$ 0.02 ) below the level in control animals, whilst in the same rats testosterone concentrations in 


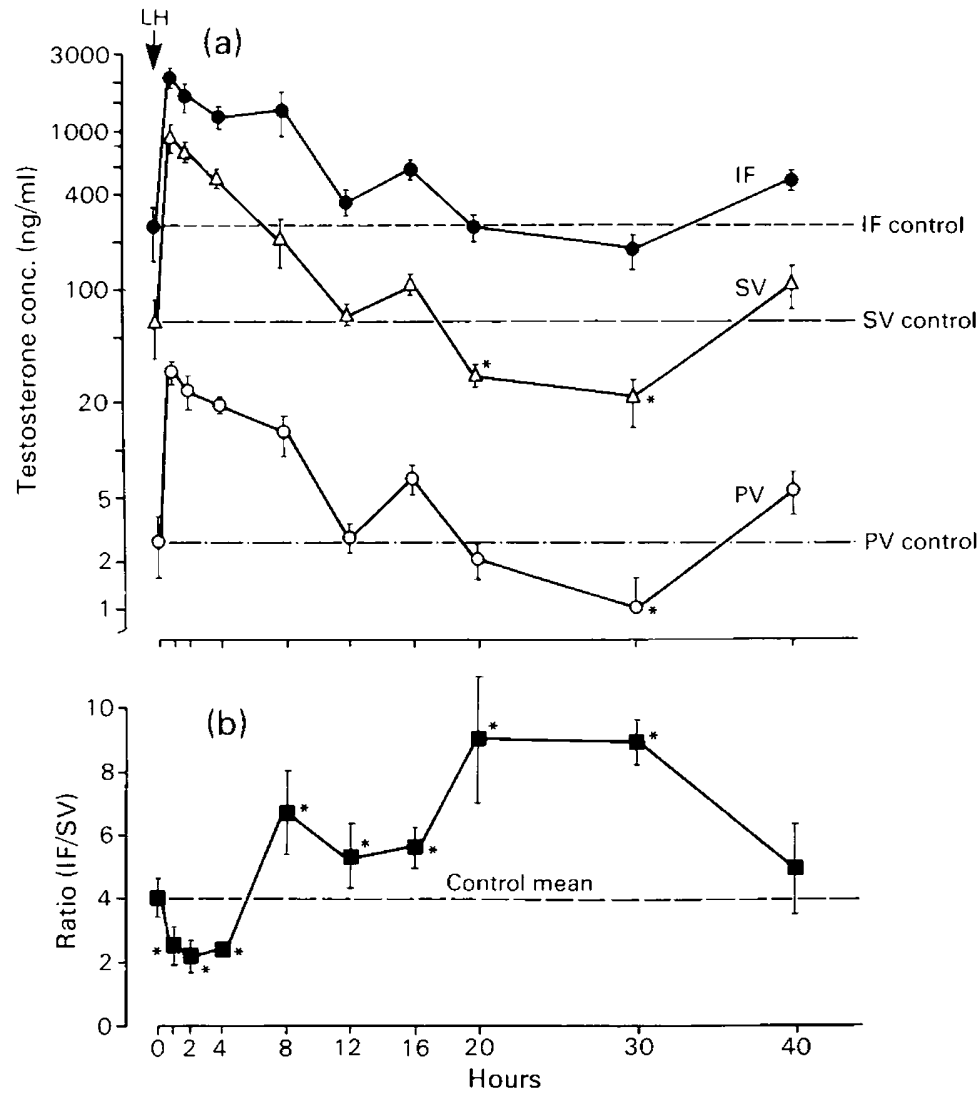

Text-fig. 3. Temporal changes in the level of testosterone in testicular interstitial fluid (IF), spermatic venous blood (SV) and peripheral venous blood (PV) after injection of adult rats with $25 \mu \mathrm{g} \mathrm{LH}$. The testosterone concentrations (a) are shown on a logarithmic scale whereas the relative concentration of testosterone in IF to that in SV (b) is shown on an arithmetic scale. Each point is the mean \pm s.d. for 3 animals except for the control values (broken lines) which are the mean \pm s.d. for 6 animals. In (a), asterisks indicate where values fell significantly $(P<$ $0.02)$ below control values; in (b) asterisks indicate where values were significantly $(P<0.05$ $P<0.001$ ) lower or higher than the corresponding control values.

interstitial fluid remained within the control range (Text-fig. 3). Similarly, when the ratio of the testosterone concentration in interstitial fluid to that in peripheral venous blood was compared, differences comparable to those illustrated for interstitial fluid/spermatic venous blood were observed whilst the spermatic/peripheral venous blood ratio of testosterone showed no significant $(P>0.05)$ variation with time after injection (data not shown). In this study, the recovered interstitial fluid volume was increased significantly $(P<0.001)$ at $4 \mathrm{~h}$ after injection of LH $(102 \pm$ $8 \mu \mathrm{l} /$ testis, compared with $62 \pm 8 \mu \mathrm{l} /$ testis in controls; mean \pm s.d.), returned to control levels briefly at $12 \mathrm{~h}$, was increased again $(P<0.05)$ at $16-20 \mathrm{~h}$ after injection $(16 \mathrm{~h}: 79 \pm 8 \mu \mathrm{l} / \mathrm{testis} ; 20$ $\mathrm{h}: 98 \pm 29 \mu \mathrm{l} /$ testis) and returned to control levels at $30-40 \mathrm{~h}$.

\section{Testosterone concentrations in interstitial fluid and serum after injection of $L H-R H$ agonist}

Injection of $5 \mathrm{ng}$ LH-RH agonist (Exp. 6) caused the expected increase in the serum concentrations of $\mathrm{LH}$, which peaked at $2 \mathrm{~h}$ and returned to control levels by $6 \mathrm{~h}$ after injection. This 
increase in LH was accompanied by a 10 -fold increase in the values of testosterone in interstitial fluid and peripheral serum (Text-fig. 4). The change in testosterone levels followed the changes in serum LH levels up to $4 \mathrm{~h}$ after injection, but at $6 \mathrm{~h}$ there was a secondary increase $(P<0.001)$ in the concentrations of testosterone in interstitial fluid and serum and even by $16 \mathrm{~h}$ testosterone levels were still raised significantly $(P<0.05)$ above control levels. This secondary increase in testosterone values occurred in the absence of any increase in the serum concentrations of LH, but was associated with a significant $(P<0.01)$ increase in the testicular interstitial fluid volume, which was first evident at $6 \mathrm{~h}$ and persisted until $16 \mathrm{~h}$ after injection (Text-fig. 4).

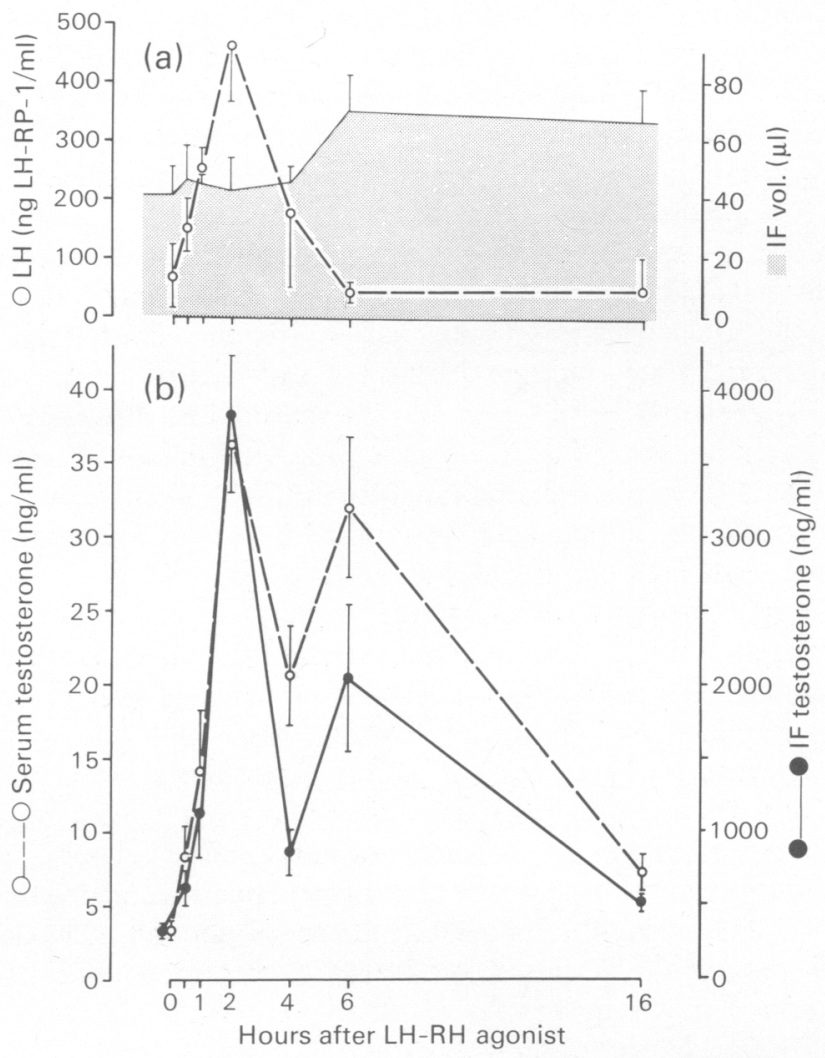

Text-fig. 4. Temporal changes in testicular interstitial fluid (IF) volume (hatched area) in relation to the serum levels of LH (a) and to the serum and IF levels of testosterone (b), after injection of adult rats with $5 \mathrm{ng} \mathrm{LH}-\mathrm{RH}$ agonist. Each point is the mean \pm s.d. for 4 rats.

\section{Discussion}

To reach their testicular targets, all blood-borne hormones and nutrients must first pass from the capiliaries into testicular interstitial fluid, and this is also the medium by which the Leydig cells and seminiferous tubules communicate (Fawcett et al., 1973; Clark, 1976). The hormonal composition of interstitial fluid provides the most accurate indication of hormone levels surrounding the Leydig cells and seminiferous tubules, whilst the volume of interstitial fluid reflects changes in the permeability of testicular capillaries (Setchell \& Sharpe, 1981). The present study provides strong 
evidence that testicular interstitial fluid which is collected by allowing fluid to drain from the incised testis offers an extremely simple means of obtaining reliable information on both of these features.

The method used for the collection of interstitial fluid is unlikely to result in $100 \%$ recovery of extracellular extratubular fluid within the testis, if only because the lymphatic sinusoids from which it must drain are discontinuous, convoluted and looped (Clark, 1976), and so pockets of interstitial fluid will remain. However, it is reasonable to expect that the volume of fluid recovered will vary in proportion to the total volume of interstitial fluid, and this was assessed by comparing the total interstitial fluid volume (i.e. the albumin space) with the volume of recovered fluid. Albumin was used as a marker because it does not penetrate into the seminiferous tubules (Setchell et al., 1976) or into cells (see Setchell, 1978; Setchell, Laurie \& Fritz, 1980), and it therefore provides an accurate assessment of the extracellular extratubular fluid volume within the testis (Setchell \& Sharpe, 1981). When the testicular extracellular fluid volume was varied over a 4- to 5-fold range (Exps 1 \& 2), the volume of recovered interstitial fluid provided an accurate reflection of changes in the total extracellular fluid volume (albumin space), despite the fact that the actual values for these two measures differed by a factor of about 2 .

The estimation of the testicular albumin space confirmed that the recovered interstitial fluid represents the interstitial fluid which bathes the outside of the seminiferous tubules rather than the fluid present within the tubule lumen. Previous studies had demonstrated this on the grounds of the composition of interstitial fluid (Sharpe, 1979), but the present finding that the ratio of the concentration of ${ }^{125}$ I-labelled BSA in serum and interstitial fluid at equilibrium never fell below 0.93 reaffirms that contamination of the recovered interstitial fluid with seminiferous tubule fluid (which will contain negligible labelled albumin) was minimal. Contamination of interstitial fluid with serum from testicular blood must also be minimal in view of the minute total blood volume contained within the testis (Setchell \& Sharpe, 1981).

The results of Exps 3-6 demonstrate that the testosterone concentration in recovered testicular interstitial fluid probably provides a reliable indication of the testosterone concentration around the Leydig cells and seminiferous tubules. Testosterone concentrations in interstitial fluid were comparable to those reported by others who obtained interstitial fluid by micropuncture of the testis (Comhaire \& Vermeulen, 1976), and the pattern of change in levels broadly paralleled those in the vasculature. In particular, the observation that changes in testosterone levels in interstitial fluid over 30- or 60-min periods closely followed those in spermatic venous or peripheral blood after stimulation with LH suggests that, despite the prolonged period over which the interstitial fluid was collected $\left(16 \mathrm{~h}\right.$ at $\left.4^{\circ} \mathrm{C}\right)$, its testosterone concentration appeared to reflect levels at the time of death. This conclusion is reinforced by our finding that testosterone concentrations in testicular extracellular fluid obtained within $45 \mathrm{~min}$ of death were similar to those in interstitial fluid collected over $16 \mathrm{~h}$ from the contralateral testis.

This study is the first to compare interstitial fluid and blood levels of testosterone and several aspects of the results are of physiological significance. The constantly higher levels of testosterone in interstitial fluid than those in spermatic venous blood indicate that testosterone values in the latter underestimate actual levels within the testis. Nor was there a constant difference or ratio between testosterone levels in interstitial fluid and spermatic venous blood (Text-fig. 3); when interstitial fluid levels of testosterone were very high, a relatively large proportion of this testosterone was secreted into the bloodstream but when interstitial fluid levels of testosterone were near normal (i.e. similar to levels in control rats), relatively little testosterone was secreted into the bloodstream. The latter finding may indicate the presence of a mechanism for conserving intratesticular testosterone concentrations, particularly because at 20-30 h after LH injection blood levels of testosterone fell significantly below control levels whilst the interstitial fluid concentration of testosterone remained within the control range. Further evidence that the proportion of testicular testosterone secreted into the bloodstream is not constant was provided by the observation that the ratio of the testosterone concentration in interstitial fluid to that in serum was 
highest in rats of 25 days of age and decreased significantly to lower levels at later ages. This change is perhaps related to the altered distribution of testicular capillaries which occurs during early puberty (Kormano, 1967).

The importance of testicular interstitial fluid as a regulator of hormone transport into the testis (Sharpe, 1981, 1983) is also illustrated in the present studies. When LH-RH agonist was injected subcutaneously to stimulate LH and hence testosterone secretion (Exp. 6), rising serum levels of LH were paralleled by rising levels of testosterone in interstitial fluid and peripheral serum up to $2 \mathrm{~h}$, but between 4 and $6 \mathrm{~h}$, when serum levels of $\mathrm{LH}$ fell below those in control animals, testosterone values in both compartments showed a secondary increase (Text-fig. 4), a change almost identical to that in immature rats injected with LH-RH agonist (Sharpe \& Fraser, 1980a). Two possible causes of this apparent 'LH-independent' increase in testosterone secretion are that it is due to (1) a direct effect of the LH-RH agonist on the Leydig cell, or (2) the associated increase in interstitial fluid volume (Text-fig. 4). Although the former option is consistent with the initial stimulatory effects of LH-RH agonist on Leydig cell testosterone secretion, the magnitude of the secondary increase in testosterone and its timing make this possibility less likely (see Sharpe, Doogan \& Cooper, 1982; Sharpe \& Harmar, 1983). In contrast, the increase in interstitial fluid volume between 4 and $6 \mathrm{~h}$ after injection of LH-RH agonist, which occurred presumably in response to the raised levels of LH (Setchell \& Sharpe, 1981), would have increased the transport of LH from the bloodstream into interstitial fluid and hence to the Leydig cells (Sharpe, 1981, 1983). Therefore, although in this experiment the serum levels of LH remained at or below control levels between 6 and $16 \mathrm{~h}$, the amount of LH reaching the Leydig cells would have been above normal due to the increase in capillary wall permeability. This re-emphasizes the potential importance of capillary wall permeability changes as a means of locally regulating gonadotrophin entry into the testis.

This study has demonstrated that the collection of interstitial fluid from the rat testis can provide a reliable guide to the total volume of testicular interstitial fluid (and thus to the permeability of testicular capillaries) and to the composition of the fluid that normally surrounds the Leydig cells and seminiferous tubules. It provides a simple means of sampling the intratesticular environment and has obvious applications in the measurement of factors such as inhibin and androgen-binding protein, which are secreted within the testis, and hormones such as testosterone, oestradiol, 'testicular LH-RH' (Sharpe \& Fraser, 1980b) and endorphins (Dong, Phillips, Halmi, Krieger \& Bardin, 1982), all of which are believed to be of importance as intratesticular communicators or regulators.

We thank Dr J. Sandow and Hoechst, A.G., for the gift of LH-RH agonist and NIAMDD, U.S.A., for the gift of bovine and ovine LH and materials for LH radioimmunoassay.

\section{References}

Clark, R.V. (1976) Three dimensional organization of testicular interstitial tissue and lymphatic space in the rat. Anat. Rec. 184, 203-226.

Comhaire, F.H. \& Vermeulen, A. (1976) Testosterone concentration in the fluids of seminiferous tubules, the interstitium and the rete testis of the rat. $J$. Endocr. 70, 229-235.

Corker, C.S. \& Davidson, D.W. (1978) Radioimmunoassay of testosterone in various biological fluids without chromatography. J. Steroid Biochem. 9, 373374.

de Kretser, D.M., Sharpe, R.M. \& Swanston, I.A. (1979) Alterations in steroidogenesis and $\mathrm{hCG}$ binding in the cryptorchid rat testis. Endocrinology 105, 135138.

Dong, T.S., Phillips, D.M., Halmi, N., Krieger, D. \&
Bardin, C.W. (1982) $\beta$-endorphin is present in the male reproductive tract of five species. Biol. Reprod. 27, 755-764.

Fawcett, D.W., Neaves, W.B. \& Flores, M.N. (1973) Comparative observations on intertubular lymphatics and the organization of the interstitial tissue of the mammalian testis. Biol. Reprod. 9, 500-532.

Fraser, H.M. \& Sandow, J. (1977) Gonadotrophin release by a highly active analogue of LHRH in rats immunized against LHRH. J. Endocr. 74, 291-296.

Furuyama, S., Mayes, D.M. \& Nugent, C.A. (1970) A radioimmunoassay for plasma testosterone. Steroids 16, 415-428.

Kormano, M. (1967) An angiographic study of the testicular vasculature in the postnatal rat. Z. Anat. Entw. Gesch. 126, 138-153. 
Miyachi, Y., Vaitukaitis, J.L., Nieschlag, E. \& Lipsett, M.B. (1972) Enzymatic radioiodination of gonadotropins. J. clin. Endocr. Metab. 34, 23-28.

Setchell, B.P. (1978) The Mammalian Testis, pp. 233-274. Paul Elek, London.

Setchell, B.P. \& Sharpe, R.M. (1981) The effect of injected human chorionic gonadotrophin on capillary permeability, extracellular fluid volume and the flow of lymph and blood in the testes of rats. J. Endocr.91, 245-254.

Setchell, B.P., Hinton, B.T., Jacks, F. \& Davies, R.V. (1976) The restricted penetration of iodinated rat FSH and LH into the seminiferous tubules of the rat testis. Molec. cell. Endocr. 6, 59-69.

Setchell, B.P., Laurie, M.S. \& Fritz, I.B. (1980) The development of the function of the blood testis barrier in rats and mice. In Testicular Development, Structure and Function, pp. 65-69. Eds E. Steinberger \& A. Steinberger. Raven Press, New York.

Sharpe, R.M. (1979) Gonadotrophin-induced accumulation of 'interstitial fluid' in the rat testis. J. Reprod. Fert. 55, 365-371.

Sharpe, R.M. (1980) Temporal relationship between interstitial fluid accumulation and changes in gonadotropin receptor numbers and steroidogenesis in the rat testis. Biol. Reprod. 22, 851-857.
Sharpe, R.M. (1981) The importance of testicular interstitial fluid in the transport of injected hCG to the Leydig cells. Int. J. Androl. 4, 64-74.

Sharpe, R.M. (1983) Impaired gonadotrophin uptake in vivo by the cryptorchid rat testis. J. Reprod. Fert. 67, 379-387.

Sharpe, R.M. \& Fraser, H.M. (1980a) Inhibition of maturational changes in Leydig cell function by treatment of rats with an agonist of LH-RH. $J$. Reprod. Fert. 60, 359-368.

Sharpe, R.M. \& Fraser, H.M. (1980b) HCG stimulation of testicular LHRH-like activity. Nature, Lond. 287, 642-643.

Sharpe, R.M. \& Harmar, A.J. (1983) The nature and biological actions of 'testicular LHRH'. In Hormones and Cell Regulation, vol. 7, pp. 217-230. Eds J. E. Dumont, J. Nunez \& R. M. Denton. Elsevier Biomedical Press, Amsterdam

Sharpe, R.M., Doogan, D.G. \& Cooper, I. (1982) Stimulation of Leydig cell testosterone secretion in vitro and in vivo in hypophysectomized rats by an agonist of luteinizing hormone releasing hormone. Biochem. biophys. Res. Commun. 106, 1210-1217.

Received 30 December 1982 